\title{
Formulation and In vitro Evaluation of Glimepiride Sustained Release Tablets: Comparison with Immediate Release Tablets
}

\author{
Samira Karim ${ }^{1,2}$, Mohiuddin Ahmed Bhuiyan ${ }^{1}$ and Md. Sohel Rana ${ }^{2}$ \\ ${ }^{1}$ Pharmaceutical Technology Research Laboratory, Department of Pharmacy, University of Asia Pacific, \\ Dhanmondi, Dhaka-1209, Bangladesh \\ ${ }^{2}$ Department of Pharmacy, Jahangirnagar University, Savar, Dhaka-1342, Bangladesh
}

Received: June 01, 2015; Accepted: June 30, 2015; Published (Web): July 21, 2015

\begin{abstract}
This work aims at the design of a sustained release formulation of glimepiride which is currently available in the treatment of type 2 diabetes mellitus and to investigate the effect of polymers on the release profile of glimepiride. Glimepiride sustained release tablets were prepared by direct compression method using different ratios of various release retarding polymers such as carbopol, ethyl cellulose, methocel K4 MCR, methocel K15 MCR, methocel K100 MCR and xanthum gum. These formulations were also compared with glimepiride immediate release tablets. The prepared tablets were subjected to various physical parameter tests including weight variation, friability, hardness, thickness, diameter, etc. In vitro dissolution studies of the formulations were done at $\mathrm{pH} 6.8$ in phosphate buffer using USP apparatus 2 (paddle method) at $50 \mathrm{rpm}$. The percent releases of all the formulations (30) were $73.11 \%$ - $98.76 \%$ after 8 hours. The release pattern followed zero order kinetics and the release of the drug was hindered by the polymers used in the study. On the other hand, 100\% drug was released within 1 hour from the immediate release tablet of glimepiride. The study reveals that the polymers used have the capacity to retard the release of the drug from the sustained release tablets and the more is the amount of the polymer in the formulation the less is the release of drug showing more retardation of drug release.
\end{abstract}

Key words: Glimepiride, sustained release tablet, direct compression method, in vitro dissolution.

\section{Introduction}

The development of oral sustained release formulation is an attempt to control the release of drug from the gastro intestinal tract (GIT) and maintain an effective drug concentration in the systematic circulation for a long time. After an oral administration such a drug will retain in the stomach, which will eventually release the drug in a controlled manner so that the drug could be supplied continuously to its absorption sites in the GIT (Streubel et al., 2006). Incomplete drug release from the dosage form in the absorption zone causes diminished efficacy of administered dose (Iannuccelli et al., 1998). Prolonged gastric retention improves bioavailability, increases the duration of drug release, reduces drug waste and improves solubility of drugs that are less soluble at high $\mathrm{pH}$ environment (Garg and Gupta, 2008). Oral drug delivery systems are matrix based requiring fewer unit operations, less machineries, reduced number of personnel and processing time, increased product stability and production rate (Reddy et al., 2003). Oral sustained release dosage form by direct compression technique is a simple approach of drug delivery due to its ease of compliance, faster production, reduced hydrolytic or oxidative degradation during processing of dosage forms (Lobenberg and Amidon, 2000). Sustained or controlled drug delivery occurs while embeded within a polymer that may be natural, semisynthetic or synthetic in nature. The polymer is judiciously combined with drug in such a manner that drug is released from the material in a predetermined and constant rate for a desired time period (Ford et al., 1985).

Glimepiride is an oral blood glucose lowering drug belonging to the third generation sulphonylurea class that is currently available for treating hyperglycemia in non insulin dependent diabetes mellitus (NIDDM). Glimepiride is classified under class II according to

Correspondence to: Md. Sohel Rana; Phone: +88-01711987016; Email: sohelrana.ju@juniv.edu 
biopharmaceutical classification systems (Kiran et al., 2009). Chemically glimepiride is

identified as 1-[[p-[2-(3-ethyl-4-methyl-2-oxo-3pyrroline-1carboxamido) ethyl] phenyl] sulfonyl]-3-(trans4-methylcyclohexyl) urea (Ning et al., 2011). It is practically insoluble in water having high cell permeability (Rajpurohit et al., 2011). It is slightly soluble in methanol and showed favorable partition coefficients (1.8 in octanol /pH 7.4 buffer) (Pachisia and Agrawal, 2012). The primary mechanism of action of glimepiride in lowering blood glucose appears to be dependent on stimulating the release of insulin from the functioning pancreatic beta cells (Rani et al., 2012). Metformin and glimepiride tablets simultaneously targets insulin resistance and insulin deficiency in type 2 diabetes, which may account for the greater effects on hyperglycemia (Pattanayak and Dinda, 2011). The aim of the present study was to design and develop the best sustained release formulations of glimepiride tablets, to evaluate the release pattern and to compare it with that of immediate release tablets. The study was designed to achieve maximum efficacy for the treatment of type 2 diabetes mellitus.

\section{Materials and Methods}

Drugs and chemicals: Glimepiride was a gift sample from White Horse Pharmaceuticals Ltd. Bangladesh. Carbopol, ethyl cellulose, methocel K4 MCR, methocel K15 MCR, methocel K100 MCR, xanthum gum and sodium starch glycolate were obtained from SKF Pharmaceuticals Ltd. and ACI Pharmaceuticals Ltd., Bangladesh. Lactose, povidone K-30 and starch were purchased from local market. The source of magnesium stearate and talc was Willfrid Smith Ltd., UK. Sodium hydroxide and potassium dihydrogen phosphate were procured from Merck, Germany. Distilled water was collected from the own research laboratory.

Formulation: In this work, the drug release patterns from various ratios (based on polymers) were studied to identify the probability of using them as sustaining agents in near future. With this view in mind, 30 formulations were designed taking glimepiride as a model drug (Table 1). For immediate release tablet only one formulation was prepared just for the comparison study using $2 \mathrm{mg}$ of glimepiride with $80 \mathrm{mg}$ povidone $\mathrm{K} 30,40 \mathrm{mg}$ sodium starch glycolate, $6 \mathrm{mg}$ magnesium stearate and starch q.s. to $380 \mathrm{mg}$ tablet.

Preparation of Glimepiride tablets: All the ingredients including active drug (glimepiride) were weighed properly, sieved and mixed thoroughly. Individually every tablet was prepared by direct compression method with a pressure of 5 ton by hand compression machine.

Measurement of physical parameters of the resulting tablets:

A) Hardness: The mechanical strength of tablets in literature has been described in a variety of ways, including hardness, tensile strength, fracture strength, crushing strength, etc. (Marshall, 1970). Six tablets of each of the formulations were taken and the hardness was measured by Schleuniger Digital tablet hardness tester, USA.

B) Thickness and diameter measurement: Twenty tablets of each of the formulation were taken and thickness and diameter were measured with the help of slide caliper.

C) Weight variation test: Twenty tablets of each formulation were weighed using an electronic balance. The mean weight was calculated.

D) Friability test: Twenty tablets of each formulation were taken for friability testing. The initial weight of each of the tablet was noted. The tablets were introduced into the rotating dram of the friability tester (Veego, India) and set to rotate at $100 \mathrm{rpm}$. At the end, the tablets were collected and reweighed. The friability was calculated as the percent of weight loss.

F) In vitro dissolution study: Dissolution tests of glimepiride sustained release tablets were carried out according to the method of Hermann et al. (2005). Phosphate buffer of $\mathrm{pH} 6.8$ was used as dissolution medium and the experiment was carried out with the USP apparatus 2 (paddle method) at $50 \mathrm{rpm}$ and $37^{\circ} \pm 0.5{ }^{\circ} \mathrm{C}$ for $8 \mathrm{hrs}$. Released drug samples from the dissolution medium were assayed at $228 \mathrm{~nm}$ using UV spectrophotometer.

\section{Results and Discussion}

Physical parameters of Glimepiride sustained release tablets: The average weights of the tablets were found to be consistent and somewhat uniform at approximately 380 
mg. The average thickness and diameter were also found to be consistent, varying between the ranges of 2.06-2.26 $\mathrm{mm}$ and 13.02-13.24 $\mathrm{mm}$, respectively (Table 2 ). On the contrary, the friability of the tablets of different formulations varied greatly ranging from $0.130-0.355 \%$.
According to some authentic references the maximum friability range should be $0.5-1 \%$ (Ashnagar et al., 2007). Since the friability values for none of the formulations exceeded $1 \%$, it did not pose any problem to the formulations.

Table 1. Formulation of glimepiride sustained release tablets based on different polymers.

\begin{tabular}{|c|c|c|c|c|c|c|c|c|c|c|c|c|}
\hline \multirow[b]{2}{*}{$\begin{array}{c}\text { Formu- } \\
\text { lation } \\
\text { code }\end{array}$} & \multirow[b]{2}{*}{$\begin{array}{l}\text { API } \\
(\mathrm{mg})\end{array}$} & \multicolumn{6}{|c|}{ Polymers } & \multirow{2}{*}{$\begin{array}{l}\text { Lac- } \\
\text { tose }\end{array}$} & \multirow{2}{*}{$\begin{array}{l}\text { Povi- } \\
\text { done } \\
\mathrm{K}-30\end{array}$} & \multirow{2}{*}{$\begin{array}{c}\mathrm{Mg}- \\
\text { stearate }\end{array}$} & \multirow[t]{2}{*}{ Talc } & \multirow{2}{*}{$\begin{array}{c}\text { Total } \\
\text { (in } \\
\mathrm{mg} \text { ) }\end{array}$} \\
\hline & & Carbopol & $\begin{array}{c}\text { Ethyl } \\
\text { cellulose }\end{array}$ & $\begin{array}{c}\text { Methocel } \\
\text { K4 } \\
\text { MCR } \\
\end{array}$ & $\begin{array}{c}\text { Methocel } \\
\text { K15 } \\
\text { MCR }\end{array}$ & $\begin{array}{c}\text { Methocel } \\
\text { K100 } \\
\text { MCR }\end{array}$ & $\begin{array}{l}\text { Xanthum } \\
\text { gum }\end{array}$ & & & & & \\
\hline F-1 & 2 & 15 & - & - & - & - & - & 308 & 40 & 10 & 5 & 380 \\
\hline F-2 & 2 & 25 & - & - & - & - & - & 298 & 40 & 10 & 5 & 380 \\
\hline F-3 & 2 & 35 & - & - & - & - & - & 288 & 40 & 10 & 5 & 380 \\
\hline F-4 & 2 & 70 & - & - & - & - & - & 253 & 40 & 10 & 5 & 380 \\
\hline F-5 & 2 & 100 & - & - & - & - & - & 223 & 40 & 10 & 5 & 380 \\
\hline F-6 & 2 & - & 15 & - & - & - & - & 308 & 40 & 10 & 5 & 380 \\
\hline F-7 & 2 & - & 25 & - & - & - & - & 298 & 40 & 10 & 5 & 380 \\
\hline F-8 & 2 & - & 35 & - & - & - & - & 288 & 40 & 10 & 5 & 380 \\
\hline F-9 & 2 & - & 70 & - & - & - & - & 253 & 40 & 10 & 5 & 380 \\
\hline F-10 & 2 & - & 100 & - & - & - & - & 223 & 40 & 10 & 5 & 380 \\
\hline F-11 & 2 & - & - & 15 & - & - & - & 308 & 40 & 10 & 5 & 380 \\
\hline F-12 & 2 & - & - & 25 & - & - & - & 298 & 40 & 10 & 5 & 380 \\
\hline F-13 & 2 & - & - & 35 & - & - & - & 288 & 40 & 10 & 5 & 380 \\
\hline F-14 & 2 & - & - & 70 & - & - & - & 253 & 40 & 10 & 5 & 380 \\
\hline F-15 & 2 & - & - & 100 & - & - & - & 223 & 40 & 10 & 5 & 380 \\
\hline F-16 & 2 & - & - & - & 15 & - & - & 308 & 40 & 10 & 5 & 380 \\
\hline F-17 & 2 & - & - & - & 25 & - & - & 298 & 40 & 10 & 5 & 380 \\
\hline F-18 & 2 & - & - & - & 35 & - & - & 288 & 40 & 10 & 5 & 380 \\
\hline F-19 & 2 & - & - & - & 70 & - & - & 253 & 40 & 10 & 5 & 380 \\
\hline F-20 & 2 & - & - & - & 100 & - & - & 223 & 40 & 10 & 5 & 380 \\
\hline F-21 & 2 & - & - & - & - & 15 & - & 308 & 40 & 10 & 5 & 380 \\
\hline F-22 & 2 & - & - & - & - & 25 & - & 298 & 40 & 10 & 5 & 380 \\
\hline F-23 & 2 & - & - & - & - & 35 & - & 288 & 40 & 10 & 5 & 380 \\
\hline F-24 & 2 & - & - & - & - & 70 & - & 253 & 40 & 10 & 5 & 380 \\
\hline F-25 & 2 & - & - & - & - & 100 & - & 223 & 40 & 10 & 5 & 380 \\
\hline F-26 & 2 & - & - & - & - & - & 15 & 308 & 40 & 10 & 5 & 380 \\
\hline F-27 & 2 & - & - & - & - & - & 25 & 298 & 40 & 10 & 5 & 380 \\
\hline F-28 & 2 & - & - & - & - & - & 35 & 288 & 40 & 10 & 5 & 380 \\
\hline F-29 & 2 & - & - & - & - & - & 70 & 253 & 40 & 10 & 5 & 380 \\
\hline F-30 & 2 & - & - & - & - & - & 100 & 223 & 40 & 10 & 5 & 380 \\
\hline
\end{tabular}

Hardness and tensile strength of the tablets: Hardness of the tablets of different formulations varied widely ranging from $6.36 \pm 0.009 \mathrm{Kg} / \mathrm{cm}^{2}$ being the lowest to $20.91 \pm 0.053 \mathrm{~kg} / \mathrm{cm}^{2}$ being the highest $(\mathrm{n}=20$, Table 3$)$. Since hardness greater than $5 \mathrm{~kg} / \mathrm{cm}^{2}$ is considered as acceptable, all the formulations therefore showed the desired hardness. The tablets of F-25 had the greatest hardness $\left(20.91 \pm 0.053 \mathrm{Kg} / \mathrm{cm}^{2}\right)$. Also it was found that when the concentration of polymer was increased, the hardness of the tablets was generally seen to be increased.

Radial tensile strength had also been observed between $0.150-0.445 \mathrm{Kg} / \mathrm{mm}^{2}$. The highest value was observed for formulation F-25 $\left(0.445 \mathrm{Kg} / \mathrm{mm}^{2}\right)$. In general, as the polymer concentration rises, the radial tensile strength is also seen to increase. Axial tensile strength was found to range from the lower limit of $0.047 \mathrm{Kg} / \mathrm{mm}^{2}$ to the upper limit of $0.151 \mathrm{Kg} / \mathrm{mm}^{2}$. The axial tensile strength followed the same trend as the radial tensile strength, with tablets of formulation F-25 possessing the highest strength $\left(0.151 \mathrm{Kg} / \mathrm{mm}^{2}\right)$.

Zero order model analysis: A drug is said to follow the zero order kinetics when the rate of release of drug is independent of the concentration of drug in the tablets. Percent release profile includes a plot of percent release of drug versus time. The dissolution data by zero order model revealed that maximum drug was released after 8 hours from the formulation F-1 (98.76\%) while formulation F-25 released only $73.11 \%$ of drug at the same time and thus showing a more sustaining action than other formulations. Figure 1 shows the zero order release 
of glimepiride from all the formulations of the present study. At low concentration of polymer, the release of drug was generally seen more and at the high concentration of polymer, the release of drug was generally seen to decrease. This was applicable for all the polymers used in the present study.

Table 2. Average weight variation, diameter, thickness and friability, hardness, radial tensile strength and axial tensile strength of the tablets of formulations F-1 to $F-30(n=20)$.

\begin{tabular}{|c|c|c|c|c|c|c|c|}
\hline $\begin{array}{l}\text { Formulation } \\
\text { code }\end{array}$ & $\begin{array}{c}\text { Average } \\
\text { weight } \\
(\mathrm{mg})\end{array}$ & $\begin{array}{c}\text { Average } \\
\text { diameter } \\
(\mathrm{mm})\end{array}$ & $\begin{array}{l}\text { Average } \\
\text { thickness } \\
(\mathrm{mm})\end{array}$ & $\begin{array}{c}\text { Average } \\
\text { friability } \\
(\%)\end{array}$ & $\begin{array}{l}\text { Hardness } \\
\left(\mathrm{Kg} / \mathrm{cm}^{2}\right)\end{array}$ & $\begin{array}{c}\text { Radial tensile } \\
\text { strength } \\
\left(\mathrm{Kg} / \mathrm{mm}^{2}\right)\end{array}$ & $\begin{array}{c}\text { Axial tensile } \\
\text { strength } \\
\left(\mathrm{Kg} / \mathrm{mm}^{2}\right)\end{array}$ \\
\hline $\mathrm{F}-1$ & $379 \pm 0.4$ & $13.02 \pm 0.09$ & $2.07 \pm 0.06$ & 0.133 & $6.36 \pm 0.009$ & 0.150 & 0.047 \\
\hline $\mathrm{F}-2$ & $376 \pm 0.3$ & $13.03 \pm 0.06$ & $2.09 \pm 0.08$ & 0.177 & $9.92 \pm 0.013$ & 0.232 & 0.074 \\
\hline $\mathrm{F}-3$ & $380 \pm 0.5$ & $13.04 \pm 0.11$ & $2.11 \pm 0.07$ & 0.135 & $10.32 \pm 0.017$ & 0.238 & 0.077 \\
\hline F-4 & $378 \pm 0.8$ & $13.10 \pm 0.22$ & $2.12 \pm 0.06$ & 0.217 & $12.66 \pm 0.008$ & 0.290 & 0.093 \\
\hline $\mathrm{F}-5$ & $381 \pm 0.9$ & $13.13 \pm 0.21$ & $2.16 \pm 0.11$ & 0.355 & $13.85 \pm 0.029$ & 0.311 & 0.102 \\
\hline F-6 & $382 \pm 0.8$ & $13.02 \pm 0.11$ & $2.06 \pm 0.15$ & 0.130 & $7.71 \pm 0.060$ & 0.183 & 0.057 \\
\hline F-7 & $379 \pm 0.5$ & $13.03 \pm 0.11$ & $2.08 \pm 0.16$ & 0.175 & $10.82 \pm 0.065$ & 0.254 & 0.081 \\
\hline $\mathrm{F}-8$ & $381 \pm 0.4$ & $13.05 \pm 0.13$ & $2.09 \pm 0.21$ & 0.131 & $11.88 \pm 0.034$ & 0.277 & 0.088 \\
\hline F-9 & $382 \pm 0.9$ & $13.07 \pm 0.13$ & $2.10 \pm 0.23$ & 0.217 & $12.82 \pm 0.037$ & 0.297 & 0.095 \\
\hline F-10 & $379 \pm 0.9$ & $13.09 \pm 0.15$ & $2.16 \pm 0.23$ & 0.352 & $14.26 \pm 0.957$ & 0.321 & 0.106 \\
\hline $\mathrm{F}-11$ & $381 \pm 0.4$ & $13.08 \pm 0.13$ & $2.09 \pm 0.07$ & 0.130 & $9.23 \pm 0.012$ & 0.215 & 0.068 \\
\hline F-12 & $378 \pm 0.8$ & $13.11 \pm 0.1$ & $2.11 \pm 0.09$ & 0.176 & $10.43 \pm 0.015$ & 0.240 & 0.077 \\
\hline F-13 & $380 \pm 0.4$ & $13.14 \pm 0.13$ & $2.13 \pm 0.12$ & 0.130 & $11.55 \pm 0.024$ & 0.262 & 0.085 \\
\hline F-14 & $381 \pm 0.9$ & $13.17 \pm 0.21$ & $2.16 \pm 0.14$ & 0.217 & $13.65 \pm 0.025$ & 0.305 & 0.100 \\
\hline F-15 & $378 \pm 0.8$ & $13.19 \pm 0.28$ & $2.20 \pm 0.22$ & 0.352 & $14.76 \pm 0.029$ & 0.324 & 0.108 \\
\hline F-16 & $382 \pm 0.8$ & $13.11 \pm 0.28$ & $2.09 \pm 0.1$ & 0.130 & $7.65 \pm 0.048$ & 0.177 & 0.056 \\
\hline F-17 & $378 \pm 0.8$ & $13.12 \pm 0.12$ & $2.12 \pm 0.2$ & 0.175 & $8.79 \pm 0.053$ & 0.201 & 0.065 \\
\hline F-18 & $380 \pm 0.4$ & $13.13 \pm 0.13$ & $2.13 \pm 0.21$ & 0.130 & $9.90 \pm 0.067$ & 0.225 & 0.073 \\
\hline F-19 & $381 \pm 0.9$ & $13.17 \pm 0.16$ & $2.15 \pm 0.24$ & 0.217 & $10.68 \pm 0.879$ & 0.240 & 0.078 \\
\hline $\mathrm{F}-20$ & $378 \pm 0.8$ & $13.18 \pm 0.25$ & $2.18 \pm 0.16$ & 0.352 & $12.75 \pm 0.910$ & 0.282 & 0.093 \\
\hline $\mathrm{F}-21$ & $380 \pm 0.4$ & $13.12 \pm 0.14$ & $2.10 \pm 0.15$ & 0.130 & $13.25 \pm 0.023$ & 0.306 & 0.098 \\
\hline $\mathrm{F}-22$ & $378 \pm 0.8$ & $13.13 \pm 0.31$ & $2.15 \pm 0.22$ & 0.175 & $16.56 \pm 0.036$ & 0.373 & 0.122 \\
\hline $\mathrm{F}-23$ & $380 \pm 0.4$ & $13.17 \pm 0.32$ & $2.16 \pm 0.31$ & 0.135 & $17.69 \pm 0.037$ & 0.396 & 0.129 \\
\hline $\mathrm{F}-24$ & $381 \pm 0.9$ & $13.21 \pm 0.31$ & $2.19 \pm 0.32$ & 0.217 & $19.78 \pm 0.040$ & 0.435 & 0.144 \\
\hline $\mathrm{F}-25$ & $378 \pm 0.8$ & $13.24 \pm 0.36$ & $2.26 \pm 0.32$ & 0.352 & $20.91 \pm 0.053$ & 0.445 & 0.151 \\
\hline F-26 & $379 \pm 0.5$ & $13.04 \pm 0.14$ & $2.08 \pm 0.08$ & 0.133 & $7.36 \pm 0.013$ & 0.172 & 0.055 \\
\hline $\mathrm{F}-27$ & $376 \pm 0.3$ & $13.05 \pm 0.16$ & $2.09 \pm 0.09$ & 0.177 & $8.60 \pm 0.025$ & 0.200 & 0.064 \\
\hline $\mathrm{F}-28$ & $381 \pm 0.5$ & $13.08 \pm 0.16$ & $2.11 \pm 0.07$ & 0.134 & $9.92 \pm 0.013$ & 0.228 & 0.073 \\
\hline F-29 & $379 \pm 0.4$ & $13.10 \pm 0.22$ & $2.12 \pm 0.06$ & 0.218 & $12.76 \pm 0.020$ & 0.292 & 0.094 \\
\hline F-30 & $382 \pm 0.9$ & $13.11 \pm 0.23$ & $2.16 \pm 0.11$ & 0.355 & $13.85 \pm 0.029$ & 0.311 & 0.102 \\
\hline
\end{tabular}

A)

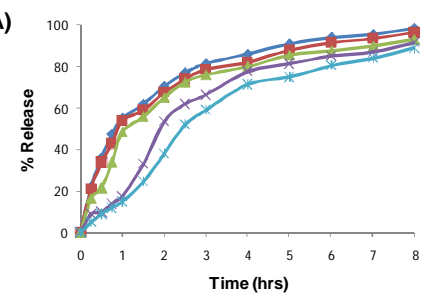

D)

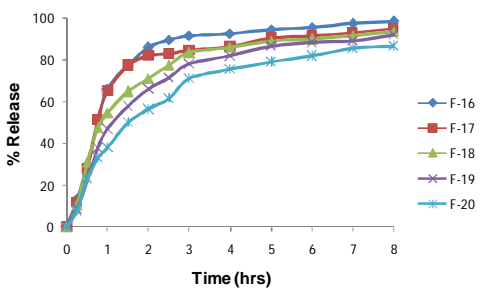

B)

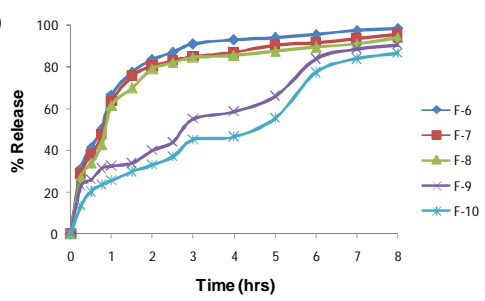

E)

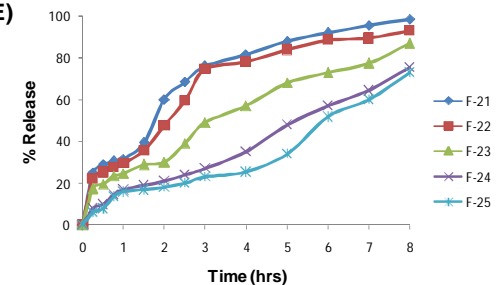

C)

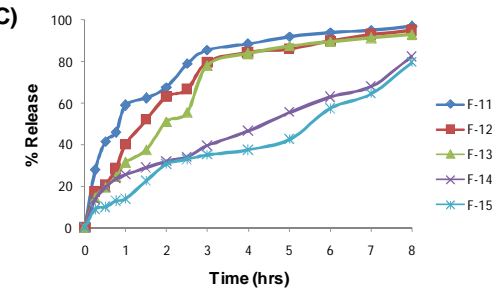

F)

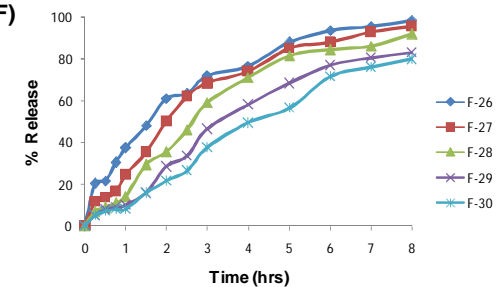

Figure 1. Zero order release of glimepiride from different formulations having different ratio of A) carbopol, B) ethyl cellulose, C) methocel K4 MCR, D) methocel K15 MCR, E) methocel K100 MCR, and F) xanthum gum. 
Release profile of Glimepiride immediate release tablets: In this research work, comparison of glimepiride for immediate release tablets has also been carried out. Drug delivery system of immediate release shows rapid and complete release of drug immediately after administration. Release profile includes a plot of percent release of drug versus time. Our values indicate that at the end of $30 \mathrm{~min}$, tablet released almost $100 \%$ of drug whereas after 5 minutes, tablet released $10.62 \%$ of drug (Figure 2). The release was high due to the presence of sodium starch glycolate which acted as a super disintegrant. So in the comparison of percent release of drugs of immediate release formulation showed that the rapid and complete release of drug occurred immediately after administration in the same manner.

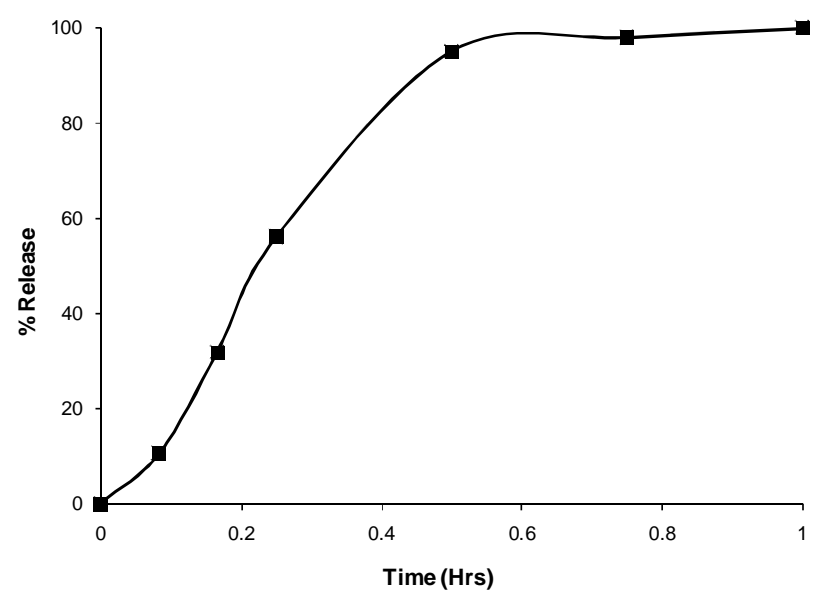

Figure 2. Percent release of immediate release formulation.

\section{Conclusion}

In vitro studies demonstrated that the release of glimepiride from all tablet formulations was generally sustained. On the other hand, the release pattern of drug was immediate in case of conventional dosage form. The release characteristics were significantly influenced by the characteristics and concentration of the polymers used. The rate of dissolution decreased as well as the sustained action of the formulation increased with the increase of polymer used in the formulations.

\section{Acknowledgements}

The authors would like to acknowledge the support received from the White Horse Pharmaceuticals Ltd., Eskayef Bangladesh Ltd. and ACI Pharmaceuticals Ltd.

\section{Conflict of Interest}

The authors declare no conflict of interest.

\section{References}

Ashnagar, A., Kouchak, M., Soltani, M. and Salimi, A. 2007. In vitro evaluation of some different brands of alprazolam tablets. J. Chem. 4, 563-573.

Ford, J.L., Rubinstein, M.H. and Hogan, J.E. 1985. Formulation of sustained release promethazine hydrochloride tablets using hydroxypropyl methyl cellulose. Int. J. Pharm. 24, 327-338.

Garg, R. and Gupta, G.D. 2008. Progress in controlled gastrorententive delivery systems. Trop. J. Pharm. Res. 7, 1055-1066.

Hermann, T.W., Dobrucki, R., Piechocki, S., Resztak, M. and Reh, R. 2005. Pharmaceutical availability of gliclazide from selected matrix formulation tablets. Med. Sci. Monitor. 11, 181-188.

Iannuccelli, V., Coppi, G., Bernabei, M.T. and Camerorni, R. 1998. Air compertment multiple-unit system for prolonged gastric residence. Part-I. Formulation study. Int. J. Pharm. 174, 47-54.

Kiran, T., Shastri, N., Ramakrishna, S. and Sadanandam, M. 2009. Surface solid dispersion of glimepiride for enhancement of dissolution rate. Int. J. Pharm. Tech. Res. 1, 822-831.

Lobenberg, R. and Amidon, G.L. 2000. Modern bioavailability, bioequivalence and biopharmaceutics classification system. New scientific approaches to international regulatory standards. Eur. J. Pharm. Biopharm. 50, 3-12.

Marshall, K. 1970. Compression and consolidation of powdered solids. In: The Theory and Practice of Indurstrial Pharmacy. Eds: Lachman, L.M., Lieberman, H.A. and Kanig, J.L. $3^{\text {rd }}$ Edn, Varghese Publishing House, Dadar Bombay, pp. 66-69.

Ning, X., Sun, J., Han, X., Wu, Y., Yan, Z., Han, J. et al. 2011. Strategies to improve dissolution and oral absorption of glimepiride tablets: solid dispersion versus micronization techniques. Drug Dev. Ind. Pharm. 37, 727-736.

Pachisia, N. and Agrawal, S.S. 2012. Formulation, development and evaluation of transdermal drug delivery system of glimepiride. Int. J. Pharm. Pharm. Sci. Res. 2, 1-8. 
Pattanayak, D.P. and Dinda, S.C. 2011. Bilayer tablet formulation of metformin hydrochloride and glimepiride: A novel approach to improve therapeutic efficacy. Int. J. Drug Disc. Herb. Res. 1, 1-4.

Rajpurohit, V.S., Rakha, P., Goyal, S., Dureja, H., Arorac, G. and Nagpal, M. 2011. Formulation and characterization of solid dispersions of glimepiride through factorial design. Iran. J. Pharm. Sci. 7, 7-16.

Rani, T.S., Sujatha, S. and Veeresham, C. 2012. Pharmacokinetic and phamacodynamic interaction of curcumin with glimepiride in normal and diabetic rats. Pharmacog. Commun. 2, 14-21.
Reddy, R.K., Mutalik, S. and Reddy, S. 2003. Once-daily sustained-release matrix tablets of nicorandil: formulation and in vitro evaluation. AAPS Pharm. Sci. Tech. 4, 480-488.

Streuble, A., Siepmann, J. and Bodmeier, R.2006. Gastroretentive drug delivery system. Exp. Opi. Drug Deliv. 3, 217-233. 